\title{
Perinatal Outcomes of Asynchronous Influenza Vaccination, Ceará, Brazil, 2013-2018
}

\author{
José Q. Filho, Francisco S. Junior, Thaisy B.R. Lima, Vânia A.F. Viana, Jaqueline S.V. Burgoa, \\ Alberto M. Soares, Álvaro M. Leite, Simone A. Herron, Hunter L. Newland, \\ Kunaal S. Sarnaik, Gabriel F. Hanson, Jason A. Papin, Sean R. Moore, Aldo A.M. Lima
}

In Ceará, Brazil, seasonal influenza transmission begins before national annual vaccination campaigns commence. To assess the perinatal consequences of this misalignment, we tracked severe acute respiratory infection (SARI), influenza, and influenza immunizations during 2013-2018. Among 3,297 SARI cases, 145 $(4.4 \%)$ occurred in pregnant women. Statewide vaccination coverage was $>80 \%$; however, national vaccination campaigns began during or after peak influenza season. Thirty to forty weeks after peak influenza season, birthweights decreased by $40 \mathrm{~g}$, and rates of prematurity increased from $10.7 \%$ to $15.5 \%$. We identified 61 children born to mothers with SARI during pregnancy; they weighed $10 \%$ less at birth and were more likely to be premature than 122 newborn controls. Mistiming of influenza vaccination campaigns adversely effects perinatal outcomes in Ceará. Because Ceará is the presumptive starting point for north-to-south seasonal influenza transmission in Brazil, earlier national immunization campaigns would provide greater protection for pregnant women and their fetuses in Ceará and beyond.

$\mathrm{R}$ espiratory infections are a leading cause of disease and death worldwide $(1,2)$, especially among young children and older adults. However, the adverse effects of respiratory infections on pregnant women and fetal development are understudied, particularly in low- and middle-income countries. Respiratory infections in pregnant

Author affiliations: Federal University of Ceará, Fortaleza, Brazil (J.Q. Filho, F.S. Junior, A.M. Soares, Á.M. Leite, A.A.M. Lima); Ceará State Health Secretariat, Fortaleza (T.B.R. Lima); Central Public Health Laboratory of Ceará, Fortaleza (V.A.F. Viana,

J.S.V. Burgoa); University of Virginia School of Medicine, Charlottesville, Virginia, USA (S.A. Herron, H.L Newland, K.S. Sarnaik, G.F. Hanson, J.A. Papin, S.R. Moore)

DOI: https://doi.org/10.3201/eid2709.203791 women can negatively affect birth outcomes, early childhood growth, and neurodevelopment (3).

Influenza epidemics are associated with excess rates of pneumonia, related hospitalizations, and death (4). Pregnant women and their infants are at heightened risk for severe influenza $(5,6)$. In 2020, Regan et al. (7) conducted a retrospective cohort study of pregnant women from Australia, Canada, Israel, and the United States; results showed hospitalizations for acute respiratory or febrile illnesses were associated with low birthweight but not small-for-gestational-age births. A prospective cohort study of pregnant women in India, Peru, and Thailand showed influenza during pregnancy is associated with late pregnancy loss and reduced mean birthweight (8). A meta-analysis (9) found that during the 2009 pandemic of influenza $\mathrm{A}(\mathrm{H} 1 \mathrm{N1}$ )pdm09, the risk for influenza hospitalization was 2-fold higher for women who were pregnant than those who were not. Children born to mothers infected during pregnancy face potential adverse consequences for physical and neurocognitive development. These consequences resemble the growth and developmental challenges described in children born to undernourished mothers in global settings with high rates of pneumonia and diarrhea (10-14).

In 2018, Almeida et al. (15) revealed that 12 of 27 states in Brazil demonstrate annual seasonal influenza activity. States along the coast generally have seasonal influenza patterns, whereas states in the North and Central West regions exhibit no readily identifiable seasonality, probably because landlocked states might have more complex and difficult to detect transmission patterns. In the semiarid state of Ceará, which has a population of $\approx 8.8$ million persons, peak seasonal influenza 
activity usually begins in mid-May, before the virus spreads southward (5). However, influenza circulation begins as early as mid-March. Fortale$\mathrm{za}$, the state capital, which has a population of 2.7 million, has seasonal influenza peaks 2-3 months earlier than in South and Southeast Brazil $(16,17)$. Despite these well-described epidemiologic differences, the entire country uses the same vaccination schedule, which is usually concurrent with or after peak influenza activity in the semiarid region (Figure 1). Because vaccine-acquired immunity against influenza usually develops 2 weeks after immunization, we hypothesized that pregnant women and their fetuses in the semiarid region might not be adequately protected against influenza.

We analyzed whether severe acute respiratory infection (SARI) during pregnancy correlated with low birthweight and premature birth in Ceará. We also evaluated the timing of national influenza vaccine campaigns relative to statewide patterns of SARI and influenza. Finally, we analyzed whether SARI during pregnancy was correlated with low birthweight and prematurity, after adjusting for known confounding variables.

\section{Methods}

\section{Ethics Approval}

We conducted this study with approval from the ethics review committees of the Federal University of Ceará (Fortaleza, Brazil) and the State Health Secretariat (Fortaleza) (registered at Coordenadoria de Gestão do Trabalho e Educação em Saúde (CTGTES)/ Nucleo de Negociação, Valorização e Educação em Saúde NUVEN). We used guaranteed public access information according to the terms of Law No. 12,527 of November 18, 2011. We also used aggregated information from deidentified databases in a manner
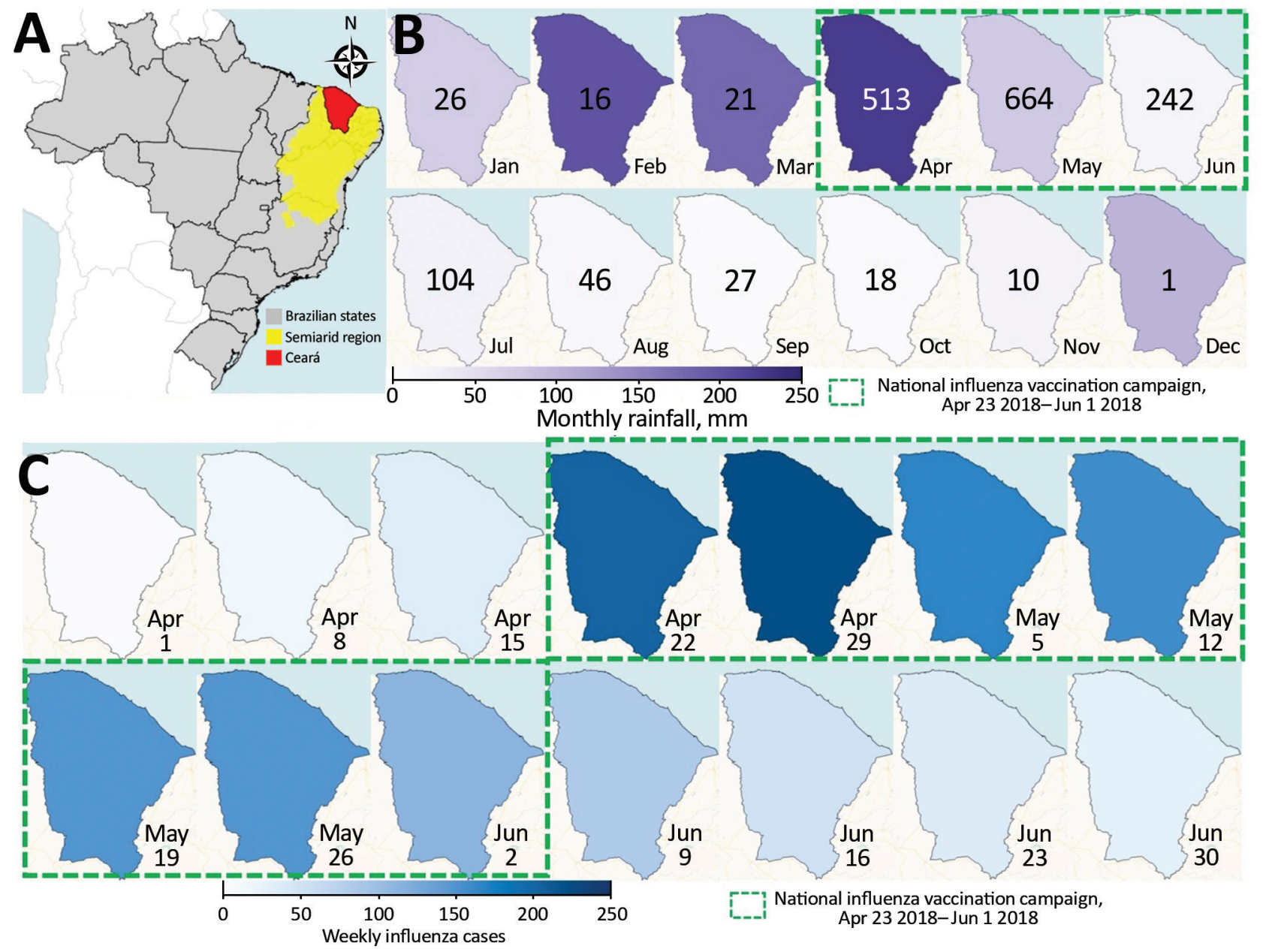

Figure 1. Seasonal patterns in rainfall and influenza and timing of influenza vaccination campaign, Ceará, Brazil, 2018. A) Location of Ceará state in the semiarid region of Brazil. B) Monthly rainfall in Ceará. Numbers indicate total influenza cases each month. C) Weekly influenza cases before, during, and after the annual vaccination campaign in Ceará. 


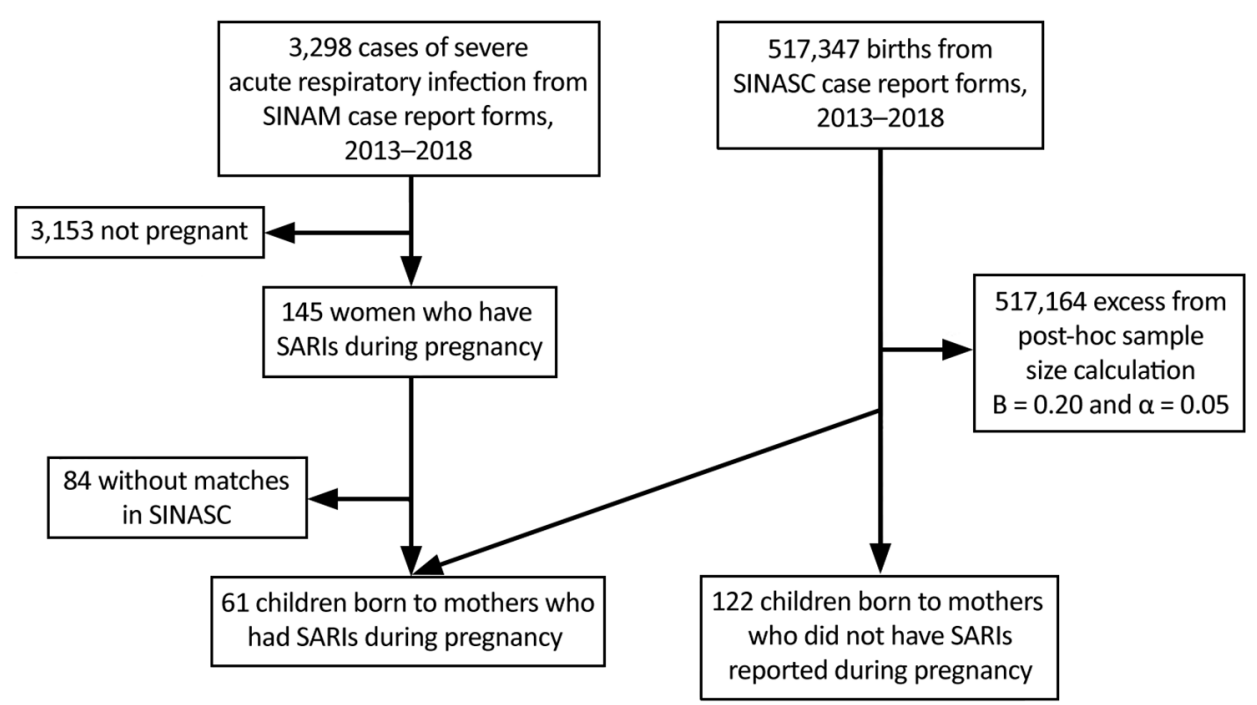

Figure 2. Design of study of SARI during pregnancy, Ceará, Brazil, 2013-2018. SARI, severe acute respiratory infection; SINASC, the Sistema de Informações Sobre Nascidos Vivos (24); SINAN, Notifiable Diseases Information System (19). consistent with the provisions of Conselho Nacional de Saúde Resolution No. 510 of April 7, 2016 (http:/ / www.conselho.saude.gov.br/resolucoes/2016/ Reso510.pdf).

\section{Study Design and Population}

Public and private hospitals are required to report SARI cases to the Ministry of Health to inform epidemic prevention, vaccine development, and vaccination campaigns (18). We identified SARI cases registered with the Notifiable Diseases Information System (SINAN-Influenza) in Ceará during 20132018 (19). We defined SARI as onset of fever (even if subjective) accompanied by cough, sore throat, dyspnea, oxygen saturation $<95 \%$, or respiratory discomfort within the preceding 7 days (20). Previous studies using multivariate regression analysis have shown that cough and fever are the best predictors of laboratory-confirmed influenza $(21,22)$. We collected data on patient demographics, education, clinical signs and symptoms, epidemiologic risk factors, vaccination status, treatments received, samples collected (i.e., nasopharyngeal secretions, bronchial aspirations, tissue, or others), and reverse transcription PCR (RT-PCR) results from SINAN-Influenza case report forms.

\section{Molecular Detection of Influenza}

RT-PCR detection of influenza viruses was based on a protocol published by the World Health Organization Global Influenza Surveillance Network (23). The RT-PCR was specific for the matrix and hemagglutinin genes of seasonal influenza A; B; H1, including $\mathrm{A}(\mathrm{H} 1 \mathrm{~N} 1) \mathrm{pdm} 09$ and $\mathrm{A}(\mathrm{H} 1 \mathrm{~N} 1) ; \mathrm{H} 3$, including $\mathrm{A}(\mathrm{H} 3 \mathrm{~N} 2)$; and avian $\mathrm{H} 5$ serotypes. Healthcare workers collected patient nasal, oropharyngeal, and nasopharyngeal swab samples and extracted nucleic acid using the QIAamp Viral Mini Kit (QIAGEN, https://www.qiagen.com) according to the manufacturer's recommended protocols. Laboratory technicians conducted RT-PCR of the extracted viral RNA, enabling production, amplification, and detection of cDNA (23).

\section{Detection of SARI during Pregnancy and Linkage to Birth Data}

We constructed a database by linking information from the SINAN-Influenza database with data from the Sistema de Informações Sobre Nascidos Vivos (SINASC) database (24). We used MySQL version 5.0.11 (Oracle Corporation, https://www.mysql. com), $R$ version 3.6.2 with the genderBR package 1.1.0 (The R Project for Statistical Computing, https:// www.r-project.org), and Stata version 11 (StataCorp LLC, https:/ / www.stata.com) to construct and manage the combined database. We compared SARI case report forms and birth records of pregnant women with documented SARI. Separately, we linked deidentified data from individual pregnant women to birth certificate data for a case-control study. When possible, we also linked influenza test results to these records. We collected each child's birthweight and Apgar score, as well as information concerning demographics, maternal education, previous and current pregnancies, and mode of delivery from birth certificate data.

\section{Maternal and Fetal Effects of SARI}

To evaluate the effects of maternal SARI on birthweight and gestational length, we designed an 
Table 1. Prevalence of severe acute respiratory infection, Ceará, Brazil, 2013-2018*

\begin{tabular}{|c|c|c|c|c|c|c|}
\hline \multirow[b]{2}{*}{ Variable } & \multicolumn{6}{|c|}{ Year } \\
\hline & 2013 & 2014 & 2015 & 2016 & 2017 & 2018 \\
\hline \multicolumn{7}{|l|}{ Sext } \\
\hline M & $141(43)$ & $68(39)$ & $115(40)$ & $272(50)$ & $150(53)$ & $854(51)$ \\
\hline $\mathrm{F}$ & $189(57)$ & $105(61)$ & $174(60)$ & $274(50)$ & $135(47)$ & $820(49)$ \\
\hline Age, y (range)‡ & $\begin{array}{c}26.02(0- \\
96)\end{array}$ & $\begin{array}{c}26.54(0- \\
97)\end{array}$ & $\begin{array}{c}23.11(0- \\
94)\end{array}$ & $\begin{array}{c}16.85(0- \\
100)\end{array}$ & $\begin{array}{c}1.58(0- \\
94)\end{array}$ & $5.26(0-102)$ \\
\hline \multicolumn{7}{|l|}{ Age groups at high risk $\dagger$} \\
\hline$<6 \mathrm{mo}$ & $47(14)$ & $46(27)$ & $76(26)$ & $52(10)$ & $88(31)$ & $235(14)$ \\
\hline $6 \mathrm{mo}$ to $5 \mathrm{y}$ & $43(13)$ & $16(9)$ & $23(8)$ & $174(32)$ & $84(29)$ & $594(35)$ \\
\hline$>60 y$ & $53(16)$ & $27(16)$ & $30(10)$ & $102(19)$ & $21(7)$ & $247(15)$ \\
\hline Pregnant woment & $38(12)$ & $13(8)$ & $32(11)$ & $17(3)$ & $10(4)$ & $35(2)$ \\
\hline SARI cases, total $\dagger$ & $330(100)$ & $173(100)$ & $289(100)$ & $546(100)$ & $285(100)$ & $1,674(100)$ \\
\hline Influenza & $56(17)$ & $24(14)$ & $58(20)$ & $107(20)$ & $36(13)$ & 451 (27) \\
\hline Noninfluenza & $61(18)$ & $22(13)$ & $36(12)$ & 64 (12) & $101(35)$ & 21 (1) \\
\hline Unspecified or unknown & $213(65)$ & $127(73)$ & $198(69)$ & $375(69)$ & $148(52)$ & $1,202(72)$ \\
\hline Influenza subtypes§ & $56(100)$ & $24(100)$ & $58(100)$ & $107(100)$ & $35(100)$ & $450(100)$ \\
\hline Seasonal $A(H 1 N 1)$ & $30(54)$ & $18(75)$ & $1(2)$ & $89(83)$ & $2(6)$ & $309(69)$ \\
\hline Other seasonal $\mathrm{A}(\mathrm{H} 1)$ & 0 & 0 & $45(78)$ & 0 & $1(3)$ & 0 \\
\hline Seasonal $A(H 3)$ & $2(4)$ & 0 & 0 & 0 & $25(71)$ & $23(5)$ \\
\hline A, unknown subtype & $22(39)$ & $1(4)$ & $4(7)$ & $16(15)$ & 0 & $14(3)$ \\
\hline B & $2(4)$ & $5(21)$ & $8(14)$ & $2(2)$ & $7(20)$ & $104(23)$ \\
\hline SARI deaths I & $13(100)$ & $2(100)$ & $1(100)$ & $40(100)$ & $24(100)$ & $159(100)$ \\
\hline Influenza & $9(69)$ & $1(50)$ & 0 & $17(43)$ & $5(21)$ & $75(47)$ \\
\hline Death rate of laboratory-certifiec & 16.1 & 4.2 & 0 & 15.9 & 20.8 & 16.6 \\
\hline Other viruses/etiologic agents or unsp & $4(31)$ & $1(50)$ & $1(100)$ & $23(58)$ & $19(79)$ & $84(53)$ \\
\hline Influenza vaccination coverage ${ }^{\star \star}$ & 88 & 84 & 83 & 91 & 90 & NA \\
\hline \multicolumn{7}{|c|}{$\begin{array}{l}\text { *Data from Notifiable Diseases Information System (19). Values are no. (\%), except as indicated. NA, not available; SARI, severe acute respiratory } \\
\text { infection. } \\
\text { †Of total SARI patients. } \\
\text { †Values are median age (range). } \\
\text { §Of total persons with identified influenza subtype. } \\
\text { †Of total SARI deaths. } \\
\text { \#Of total laboratory-certified influenza deaths. } \\
\text { **Among persons at risk (estimated at } \approx 2.6 \text { million). Population at risk comprises children }<6 \text { mo of age; children } 6 \text { mo to }<5 \text { y of age; persons } \geq 60 \text { years } \\
\text { of age; pregnant women; postpartum women ( } \leq 45 \mathrm{~d} \text { after delivery); healthcare workers; teachers; indigenous persons; persons who have chronic } \\
\text { noncommunicable diseases and other immunocompromising conditions; persons } 12-21 \text { y of age experiencing poverty; prisoners; prison system officials; } \\
\text { and military police, civilians, firefighters, and armed forces. }\end{array}$} \\
\hline
\end{tabular}

observational descriptive study of children born to mothers who did and did not have SARI during pregnancy. The control group was composed of randomly selected children born to mothers matched by age ( $\leq 3$ months) to mothers who had SARI during pregnancy. We collected birthweights from SINAN data recorded during routine clinical practice.

\section{Annual Periodicity in Birthweight and Gestational Length}

To evaluate the effects of seasonal influenza on birth outcomes, we investigated the periodicity associated with birthweight and gestation length in Ceará. We obtained birth outcomes from the SINASC database. SINASC classifies gestational length using a scale of 1-6 in which 1 indicates $<22$ weeks, 2 indicates 22-27 weeks, 3 indicates 28-31 weeks, 4 indicates 32-36 weeks, 5 indicates 37-41 weeks, and 6 indicates $\geq 42$ weeks of gestation. We defined preterm birth as $<37$ weeks' gestation. We calculated the average birthweights and gestations by epidemiologic week.

\section{Sample Size and Statistical Analysis}

We estimated the sample size needed to detect an effect of SARI on birthweight would be 183 children: 61 born to mothers who did and 122 born to mothers who did not have SARI during pregnancy (Figure 2). This sample size provided a statistical power of $80 \%$ at $p<0.05$ for children who were $10 \%$ underweight compared with controls $(21,23)$. We compared mean birthweight using the formula $\mathrm{n}_{1}=(u+v)^{2}\left(\sigma_{1}^{2}+\sigma_{2}^{2} / K\right) /\left(\mu_{1}\right.$ $\left.-\mu_{2}\right)^{2}$, where $\mu_{1}-\mu_{2}$ represents the difference between means, $\sigma_{1}$ and $\sigma_{2}$ represent SDs, $u$ represents the 1-sided percentage point of the normal distribution corresponding to $100 \%$ (e.g., if power $=80 \%$, then $u=0.84), v$ represents the percentage point of the normal distribution corresponding to the 2-sided significance level (e.g., if significance level $=5 \%$, then $v=1.96)$, and $K=n_{2} / n_{1}$. We used ClinCalc.com (https://clincalc.com/Stats/SampleSize.aspx) for sample size calculations.

Data were entered into spreadsheets and checked by 2 independent researchers to ensure accuracy. All data were deidentified. We conducted statistical analysis using SPSS Statistics 20.0 (IBM 

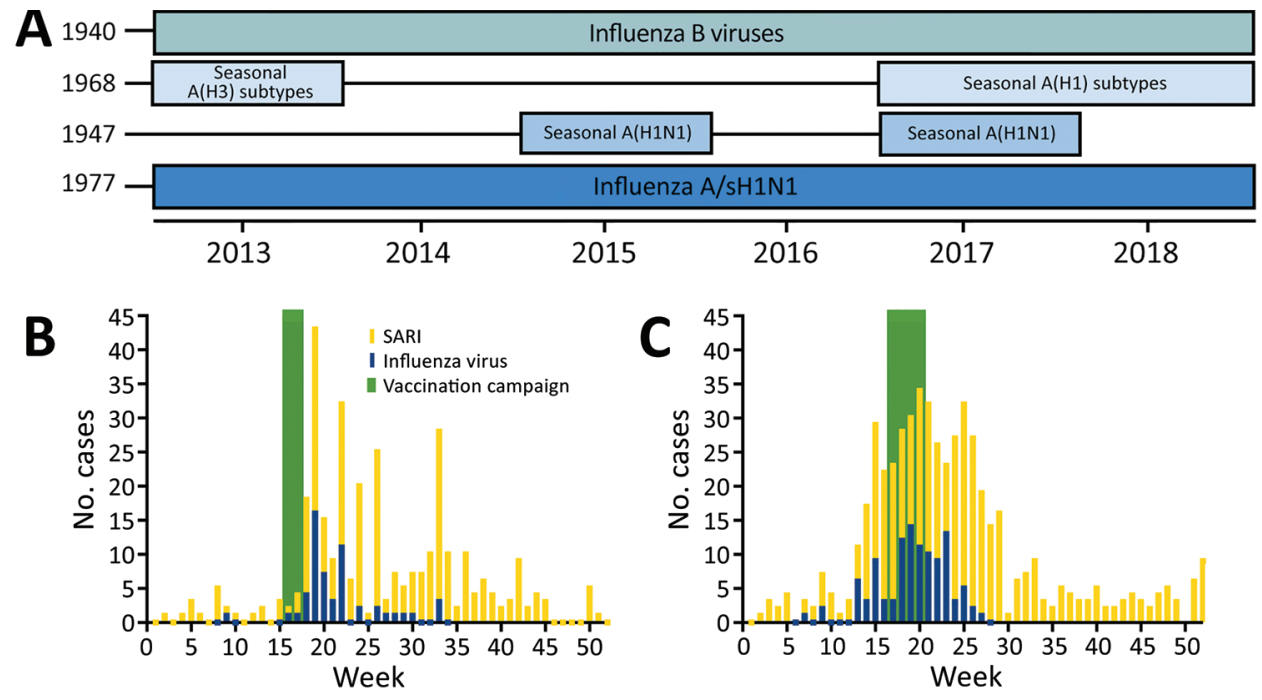

Figure 3. Patterns of influenza and severe acute respiratory infections and timing of influenza vaccination campaigns, Ceará, Brazil, 2013-2018. A) Dominance of various influenza subtypes over time. Years indicate date each strain was first identified. B) Weekly cases of influenza and severe acute respiratory infections.
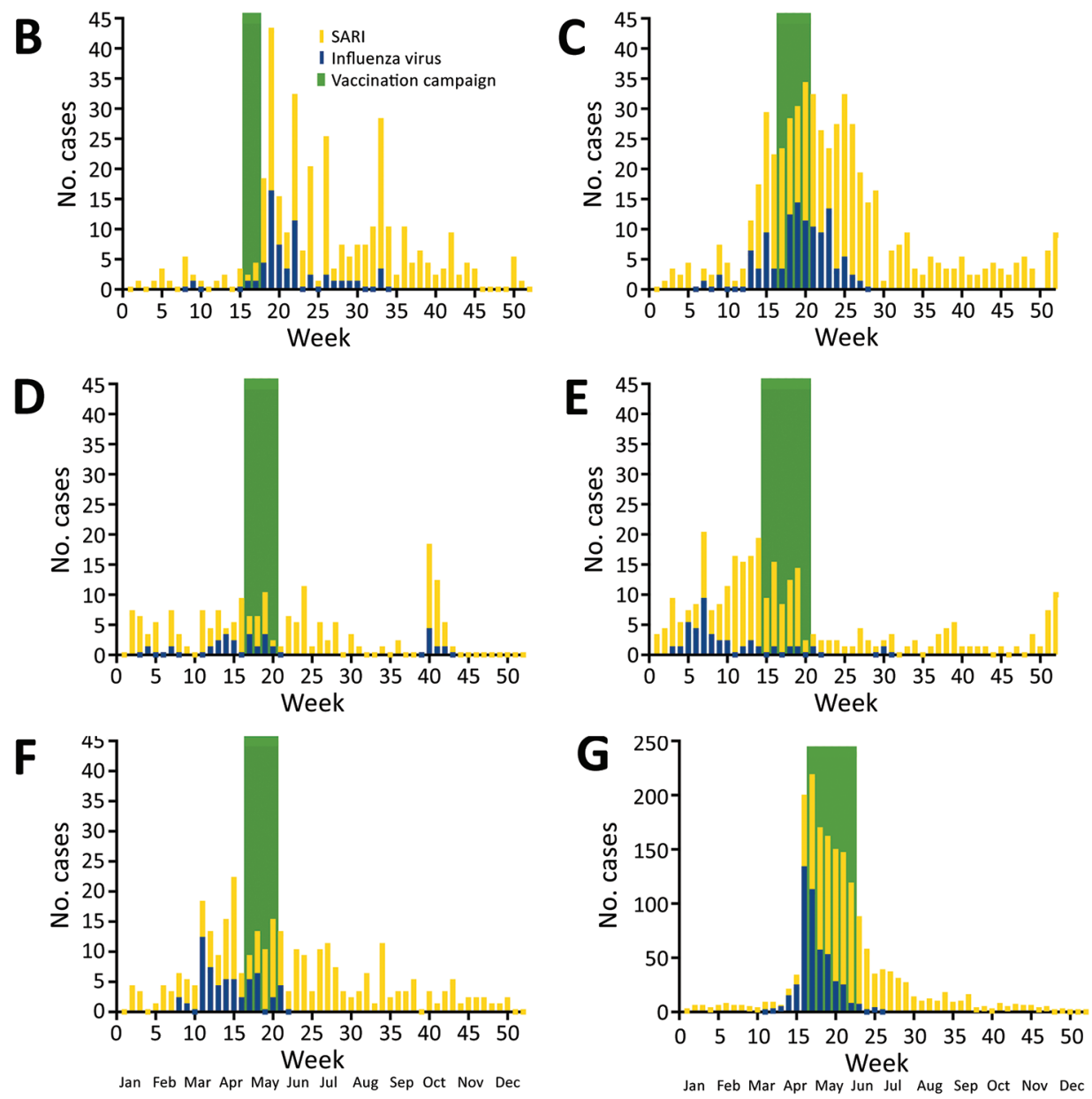

Corporation, https://www.ibm.com). We used the Shapiro-Wilk test to evaluate normality of quantitative data and the Levene test to evaluate equality of variances. For nonparametric variables, we used the Mann-Whitney test. We analyzed qualitative variables using the $\chi^{2}$ test or Fisher exact test. We used GraphPad Prism version 3.0 for Windows (GraphPad Software, https://www.graphpad. com) for complementary statistical analysis, table formatting, and figure creation. We used adjusted and nonadjusted multivariate logistic regression models to assess underweight and preterm birth associations. To reduce possible influence from confounding variables, we coadjusted variables measuring sex, maternal education, information from previous and current pregnancies, and delivery data. We used odds ratios or relative risk ratios with $95 \%$ CIs to assess the relationship between a variable and its outcome. All statistical tests were 2 -sided with a significance level of $\mathrm{p}<0.05$.

\section{Results}

Using the SINAN database, we identified 3,298 SARI cases in Ceará during 2013-2018, including 145 cases among pregnant women (Table 1). We linked the SINAN and SINASC databases to identify 61 children born to mothers who had $\geq 1$ SARI during pregnancy. We used the same databases to identify 122 children born to age-matched pregnant women who did not have recorded SARI during pregnancy. 
Table 2. Characteristics of pregnant women with SARI, Ceará, Brazil, 2013-2018*

\begin{tabular}{lc}
\hline Characteristic & Value \\
\hline Total SARI cases & $3,297(100)$ \\
Among pregnant women & $145(4)$ \\
\hline Median age, y (range) & 25.95 \\
& $(15-44)$ \\
\hline SARI cases with etiologic testing & $134(100)$ \\
Influenza & $43(32)$ \\
Noninfluenza & $11(8)$ \\
Unspecified or unknown & $80(60)$ \\
\% Laboratory-confirmed influenza & 32.1 \\
\hline Influenza subtypes $\dagger$ & $43(100)$ \\
Seasonal A(H1N1) & $18(42)$ \\
Other seasonal A(H1) & 0 \\
Seasonal A(H3) & $14(33)$ \\
A (unknown subtype) & $3(7)$ \\
B & $8(19)$ \\
\hline SARI deaths $\ddagger$ & $3(100)$ \\
Influenza & 0 \\
Death rate of laboratory-certified influenza & 0 \\
Other viruses/etiologic agents or unspecified & $3(100)$ \\
\hline${ }^{*}$ Data from Notifiable Diseases Information System (19). Values are no. \\
(\%), except as indicated. SARI, severe acute respiratory infection. \\
tOf total persons with identified influenza subtype. \\
$\ddagger$ Of total SARI deaths.
\end{tabular}

We observed equal proportions of SARI cases among male and female patients registered in the SINAN database of 3,298 overall SARI cases in Ceará. Children $<5$ years of age comprised $27 \%-61 \%$ of patients; children $<6$ months of age comprised $10 \%-31 \%$ of patients. Older adults $(7 \%-32 \%)$ and pregnant women $(2 \%-38 \%)$ also comprised large proportions of patients. We observed cases of seasonal H1N1 throughout the study period, notably in 2013 (54\%), $2014(75 \%), 2016(83 \%)$, and 2018 (69\%). The highest number of SARI cases occurred in 2018, mostly caused by seasonal H1N1 and influenza B viruses (23\%). We observed sporadic cases of seasonal influenza caused by other H1 subtypes in 2015 and 2017 and seasonal H3 subtypes in 2013 and 2017-2018 (Table 1; Figure 3, panels A, B). Influenza death rates varied from $0 \%-$ $21 \%$; the peak death rate occurred during a season predominated by $\mathrm{H} 3$ subtypes.

The median age of pregnant women who had SARI was 26 years (range 15-44 years). Among 145 pregnant women who had SARI, 43 (32\%) had laboratory-confirmed influenza. Among those 43 women, $42 \%$ had illnesses caused by H1N1, 33\% by H3 subtypes, $7 \%$ by influenza A viruses without an identified subtype, and 19\% by influenza B subtypes (19\%). We identified no deaths caused by SARI in pregnant women (Table 2).

To better visualize the relationship between birth outcomes, SARI, and influenza, we overlaid sets of data for 2018 on the same plot (Figure 4, panel A). We found that average birthweight decreased shortly before influenza season. During 2018, birth- weight peaked in the first week of the year. By week 15 , average birthweight had fallen by $\approx 40 \mathrm{~g}$ (Figure 4, panel A). After the influenza vaccination campaign ended, SARI cases declined and birthweights returned to their yearly averages. For all years of the study, we found lower average gestational scores, which indicates a higher proportion of preterm births, before and during influenza season (Figure 4, panel B).

Each year, average birthweights oscillated by up to $40 \mathrm{~g}$, or $1 \%-2 \%$ of total birthweight (Figure 5). In February, a month associated with worse birth outcomes, $15.5 \%(8,399 / 54,311)$ of children were born prematurely (<37 weeks), whereas in October, a month associated with better birth outcomes, 10.7\% $(6,552 / 61,067)$ of children were born prematurely. These data indicate that circannual oscillations in birth outcomes might be associated with SARI and seasonal influenza in Ceará.

Children born to mothers who had SARI during pregnancy had significantly lower birthweights $(\mathrm{p}=$ $0.02)$, higher risk for prematurity $(p=0.03)$, shorter gestation times $(p<0.01)$, and lower Apgar scores at 5 minutes after birth than children in the control group $(p<0.01)$. Mothers who had SARI during pregnancy had significantly less formal education than mothers who did not have SARI $(p<0.01)$. Mothers with SARI had a significantly lower number of previous pregnancies $(p=0.01)$, previous vaginal births $(p<0.01)$, and previous live births $(p=0.01)$. Mothers with SARI had a higher number of previous cesarean sections $(p<0.01)$. Cesarean deliveries and medical assistance were more frequent in cases versus controls $(86.7 \%$ vs. $0.8 \%$; $\mathrm{p}<0.01$ ) (Table 3$)$.

We used multiple logistic regression to identify predictor variables independently associated with SARI during pregnancy. First, we examined 11 significant variables identified by univariate analysis (Table 3), of which 5 showed $>40 \%$ collinearity. We had an adequate sample size (123 cases) to run a logistic regression for these 5 variables $(23,25)$. The overall model fit showed a $\chi^{2}$ value of $23.135(\mathrm{df}=6$; $\mathrm{p}<0.01$ ). The Cox and Snell test and Nagelkerke test indicated variances between $17.1 \%$ and $23.2 \%$. Including predictor variables increased model accuracy from $61 \%$ to $68 \%$. We found that birthweight $(p=0.03)$ and attendance of birth by a physician $(p=0.04)$ were significantly associated with SARI during pregnancy (Table 4; Figure 6).

\section{Discussion}

We documented 3,298 SARI cases in Ceará, Brazil, during 2013-2018. Cases occurred predominantly 


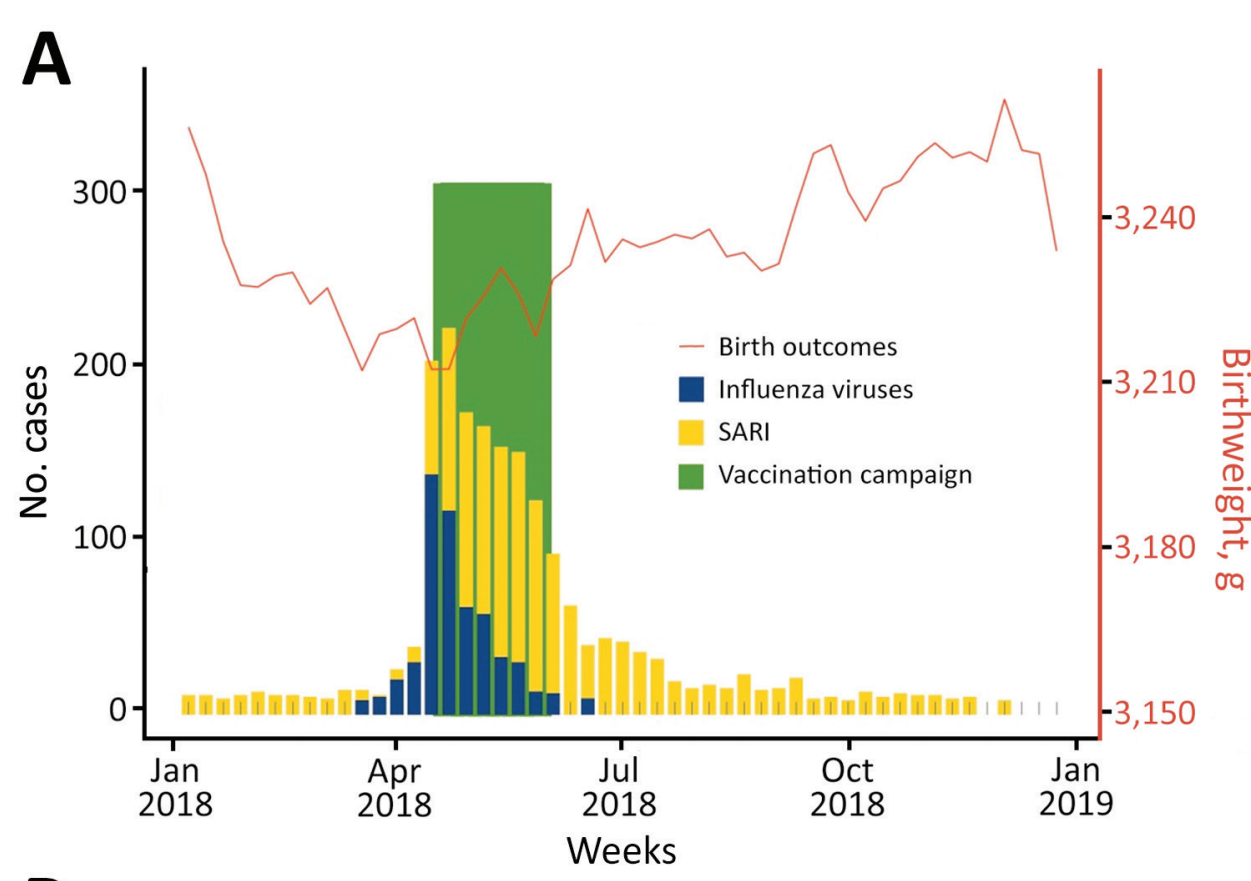

Figure 4. Associations between SARI among pregnant women and birth outcomes, Ceará, Brazil, 2018. A) By birthweight; B) by gestational score. Gestational length scored using a 1-6 scale in which 1 indicates $<22$ weeks, 2 indicates 22-27 weeks, 3 indicates 28-31 weeks, 4 indicates $32-36$ weeks, 5

indicates $37-41$ weeks, and 6 indicates $>42$ weeks of gestation. SARI, severe acute respiratory infection.

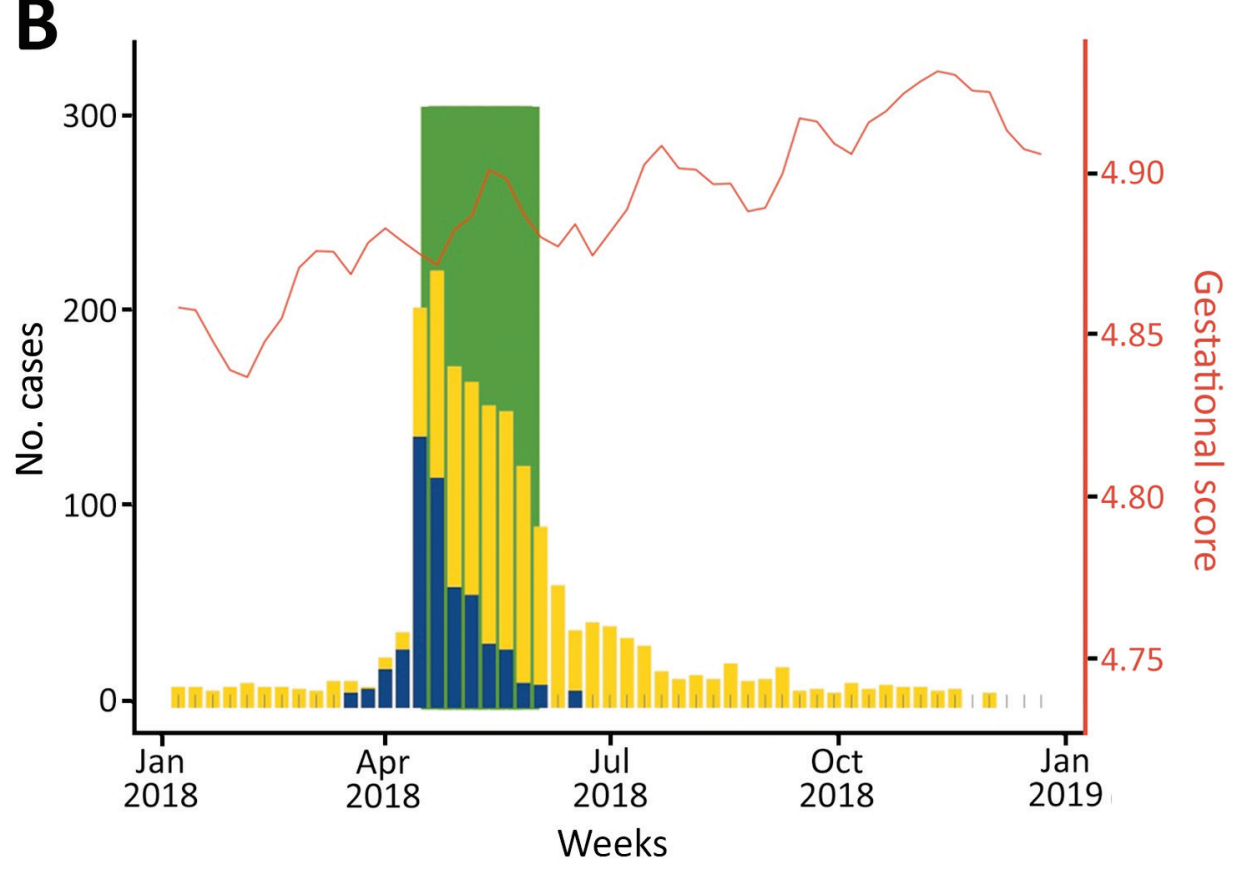

in younger children, especially children $<6$ months of age, as well as older adults and pregnant women. These data are consistent with previous studies showing higher rates of infection among younger populations but increased death rates among older adults (26).

H1N1 was the dominant influenza subtype during seasonal epidemic outbreaks, illustrating the capacity of this strain to recirculate and co-circulate with other seasonal influenza strains (Table 1; Figure
3, panel A). H1N1 caused a high death rate throughout the study. However, in 2015, when seasonal H1 strains predominated in Ceará, we observed a lower overall death rate among influenza patients. These data are consistent with prior literature showing more deaths associated with H1N1 (27). The mortality rate in our study might be attributable to the mistiming of vaccination campaigns, which occurred during and after peak influenza activity in Ceará. The state has high vaccination coverage, suggesting that 

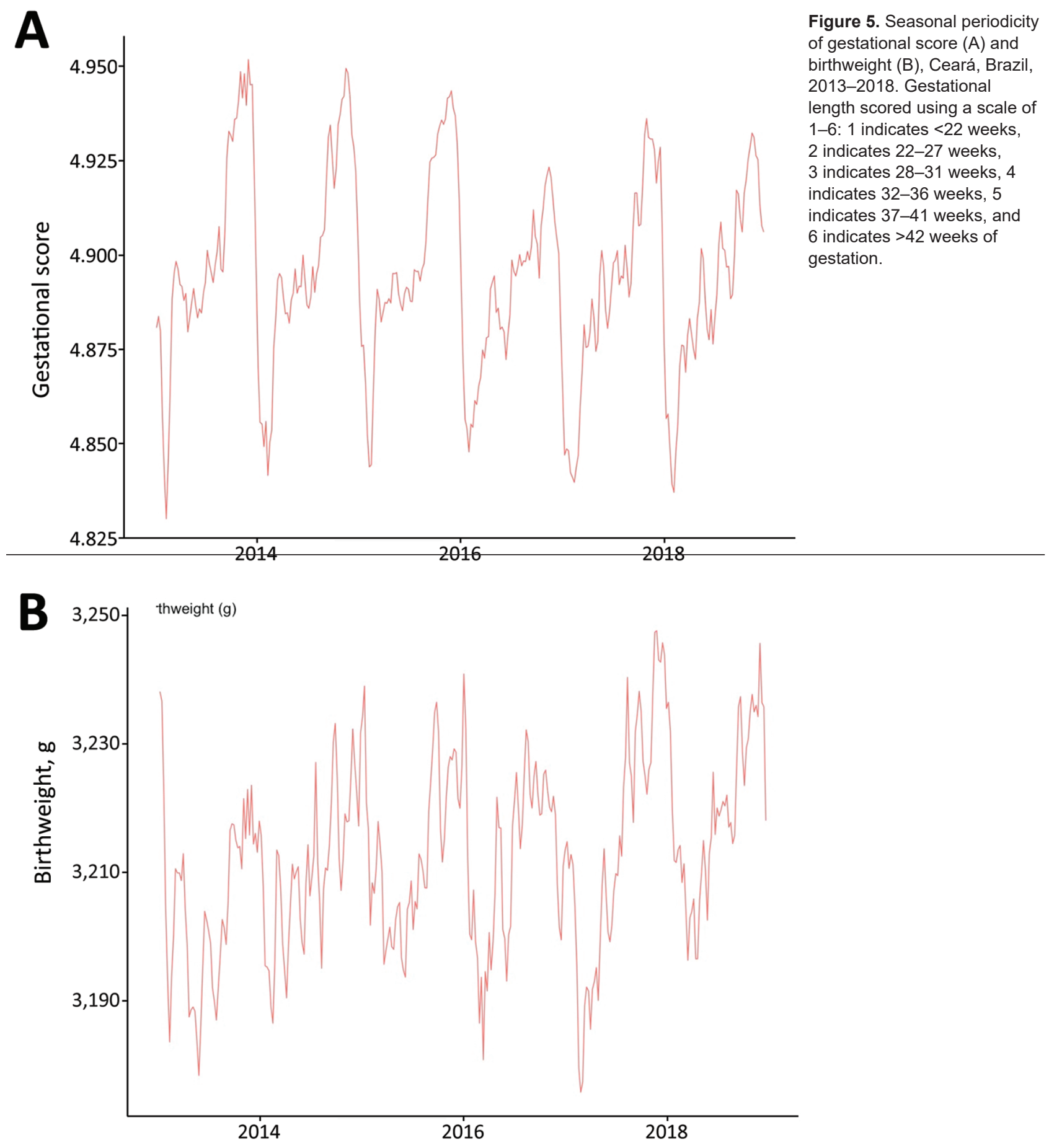

earlier administration of influenza vaccines might reduce death and disease. Mistiming of immunization schedules also might explain the unusually high disease incidence among infants $<6$ months of age. The World Health Organization does not recommend immunization in this age group. Consequently, immunization of pregnant mothers is especially crucial for passive immunity against influenza during the first 6 months of life.

In this study, we assessed whether SARI during pregnancy was associated with a higher risk for low birthweight or prematurity. We found statewide correlations between peak influenza activity and nadirs in birthweight and gestational length. Furthermore, 
we confirmed associations of maternal SARI with low birthweight and preterm birth in matched motherinfant pairs. These associations remained significant when adjusted for confounders by multiple logistic regression. Our findings agree with 2 recently published studies $(7,8)$ showing an association of SARI, including influenza, among pregnant women with low birthweights. Pregnant mothers who had SARI were more likely to require medical assistance during labor than those who did not have SARI.

Our study aligns with earlier reports showing the importance of prevention and adjustment of

\begin{tabular}{|c|c|c|c|c|}
\hline \multirow[b]{2}{*}{ Variables } & \multirow[b]{2}{*}{ Total } & \multicolumn{2}{|c|}{$\begin{array}{l}\text { Born to mothers who had severe acute } \\
\text { respiratory infections during pregnancy }\end{array}$} & \multirow[b]{2}{*}{$\mathrm{p}$ value } \\
\hline & & Yes & No & \\
\hline Total & 183 & 61 & 122 & \\
\hline \multicolumn{5}{|l|}{ Sex } \\
\hline M & $81(44)$ & $24(39)$ & $57(47)$ & 0.20 \\
\hline $\mathrm{F}$ & $102(56)$ & $378(61)$ & $65(53)$ & \\
\hline Mean birthweight, g (SD) & $3,090.1(665.42)$ & $2,879.1(783.57)$ & $3,195.6(572.61)$ & 0.02 \\
\hline Preterm birth (i.e., gestation < 37 wks) & $26(14)$ & $16(27)$ & $10(13)$ & 0.03 \\
\hline \multicolumn{5}{|l|}{ Mean Apgar index (SD) } \\
\hline At $1 \mathrm{~min}$ & $8.0(1.45)$ & $7.9(1.66)$ & $8.0(1.32)$ & 0.83 \\
\hline At $5 \mathrm{~min}$ & $9.0(0.98)$ & $8.9(0.75)$ & $9.1(1.08)$ & $<0.01$ \\
\hline Mean maternal age, y (SD) & $28.3(6.65)$ & $28.3(6.69)$ & $28.3(6.66)$ & 0.98 \\
\hline Education & & & & $<0.01$ \\
\hline None & 0 & 0 & 0 & \\
\hline Elementary I: $\leq 4$ th grade & $8(4.6)$ & $1(1.7)$ & $7(6.0)$ & \\
\hline Elementary II: $\leq 8$ th grade & 19 (10.9) & $1(1.7)$ & $18(15.5)$ & \\
\hline Secondary: $\leq 12$ th grade & $60(34.5)$ & $14(24.1)$ & $46(39.7)$ & \\
\hline Partial college & $73(42.0)$ & $34(58.6)$ & 39 (33.6) & \\
\hline College & $14(8.0)$ & $8(13.8)$ & $6(5.2)$ & \\
\hline \multicolumn{5}{|l|}{ Previous pregnancies } \\
\hline Median no. previous pregnancies (range) & $2(0-16)$ & $1(0-7)$ & $2(0-16)$ & 0.01 \\
\hline Median no. vaginal deliveries (range) & $2(0-12)$ & $0(0-4)$ & $2(0-12)$ & $<0.01$ \\
\hline Median no. cesarean sections (range) & $0(0-4)$ & $0(0-4)$ & $0(0-2)$ & $<0.01$ \\
\hline Median no. live births (range) & $2(0-12)$ & $1(0-7)$ & $2(0-12)$ & 0.01 \\
\hline Median no. fetal losses or abortions (range) & $0(0-4)$ & $0(0-2)$ & $0(0-4)$ & 0.16 \\
\hline \multicolumn{5}{|l|}{ Current pregnancy } \\
\hline Mean gestation length, wks (SD) & $37.8(3.15)$ & $36.9(3.72)$ & $38.4(2.50)$ & $<0.01$ \\
\hline Mean no. prenatal consultations (SD) & $6.9(3.15)$ & $7.0(2.55)$ & $6.7(2.16)$ & 0.56 \\
\hline Mean start of prenatal care started, mo (SD) & $2.9(1.38)$ & $2.8(1.22)$ & $3.1(1.48)$ & 0.14 \\
\hline Type of pregnancy & & & & 0.11 \\
\hline Single & $181(98.9)$ & $59(96.7)$ & $122(100)$ & \\
\hline Twins & $2(1.1)$ & $2(3.3)$ & 0 & \\
\hline Triplets or more & 0 & 0 & 0 & \\
\hline Fetal presentation at delivery $\ddagger$ & & & & 0.09 \\
\hline Cephalic & $138(96.5)$ & $54(93.1)$ & $84(98.8)$ & \\
\hline Pelvic or podalic & $5(3.5)$ & $4(6.9)$ & $1(1.2)$ & \\
\hline Transversal & 0 & 0 & 0 & \\
\hline Induced labor & & & & 0.10 \\
\hline $\mathrm{Y}$ & $5(3.6)$ & $4(6.9)$ & $1(1.2)$ & \\
\hline $\mathrm{N}$ & $134(96.4)$ & $54(93.1)$ & $80(98.8)$ & \\
\hline Type of delivery§ & & & & $<0.01$ \\
\hline Vaginal & $128(70.7)$ & $8(13.3)$ & $120(99.2)$ & \\
\hline Cesarean & $53(29.3)$ & $52(86.7)$ & $1(0.8)$ & \\
\hline Cesarean section without laborף & & & & NS \\
\hline Y & $29(76.3)$ & $29(76.3)$ & 0 & \\
\hline $\mathrm{N}$ & $9(23.7)$ & $9(23.7)^{\prime}$ & 0 & \\
\hline Birth attendant\# & & & & 0.01 \\
\hline Doctor & $122(84.1)$ & $59(98.3)$ & $63(74.1)$ & \\
\hline Obstetric nurse & $6(4.1)$ & $1(1.7)$ & $5(5.9)$ & \\
\hline Midwife & $9(6.2)$ & 0 & $9(10.6)$ & \\
\hline Others & $8(5.5)$ & 0 & $8(9.4)$ & \\
\hline $\begin{array}{l}\text { *Data from Sistema de Informações Sobre Nascidos } V \\
\text { †Mann-Whitney test was used for variables whose dist } \\
\text { †Of } 143 \text { cases with available data. } \\
\text { §Of } 181 \text { cases with available data. } \\
\text { TOf } 38 \text { cases with available data. } \\
\text { \#Of } 135 \text { cases with available data. }\end{array}$ & $\begin{array}{l}\text { lues are no. (\%), } \\
\text { not normal and } \mathrm{X}\end{array}$ & $\begin{array}{l}\text { as indicated. NS, } \\
\text { sis was used for n }\end{array}$ & $\begin{array}{l}\text { icant. } \\
\text { istributed data. }\end{array}$ & \\
\hline
\end{tabular}


Table 4. Odds ratios for characteristics of 61 children born to women who had SARI during pregnancy compared with 122 children born to women who did not have SARI, Ceará, Brazil, 2013-2018*

\begin{tabular}{|c|c|c|}
\hline Variables & Odds ratio $(95 \% \mathrm{Cl})$ & Adjusted odds ratio $(95 \% \mathrm{Cl})^{*}$ \\
\hline Birthweight, g† & 0.999 (0.999-1.000) & $0.999(0.998-1.000)$ \\
\hline Preterm birth (i.e., gestation <37 wks) $\ddagger$ & $2.944(1.100-7.879)$ & $0.849(0.151-4.771)$ \\
\hline Mother education & $4.320(1.095-17.051)$ & $1.156(0.198-6.746)$ \\
\hline No. previous pregnancies & $0.795(0.659-0.960)$ & $0.894(0.727-1.099)$ \\
\hline No. wks gestation† & $0.852(0.756-0.961)$ & $1.025(0.794-1.325)$ \\
\hline Birth attended & $20.603(2.692-157.697)$ & $9.327(1.144-76.060)$ \\
\hline \multicolumn{3}{|c|}{$\begin{array}{l}\text { *Data from Sistema de Informações Sobre Nascidos Vivos (24). SARI, severe acute respiratory infection. } \\
\text { *Determined by multivariate logistic regression analysis of variables associated with births requiring the presence of a skilled attendant. } \\
\text { †Analysis of means and SDs. } \\
\text { †Categories comprise children born at }<37 \text { and } \geq 37 \text { wks gestation. } \\
\text { §Categories comprise mothers who had attended no schooling, elementary I (1st-4th grade), elementary II (5th-8th grade), secondary school (9th-12th } \\
\text { grade), incomplete college, and complete college. Analysis grouped no schooling, elementary I (1st-4th grade), elementary II (5th-8th grade), and } \\
\text { secondary school (9th-12th grade), as well as incomplete and complete higher education categories. } \\
\text { ॠAnalysis of medians and variations. } \\
\text { \#Categories comprise births attended by a physician, obstetric nurse, midwife, or other. Analysis grouped obstetric nurse, midwife, and other categories. }\end{array}$} \\
\hline
\end{tabular}

influenza vaccine campaign schedules to avoid complications of influenza $(6,28-31)$. Previous studies show the importance of the first 1,000 days of life in reducing undernutrition, enteric infections, and risk for metabolic syndrome and cardiovascular diseases $(32,33)$. Neurocognitive, physical, and educational deficits have been well-documented among children exposed in utero or during the first months of life to influenza and other diseases such as enteric infections $(10-12,34)$.

The first limitation of our study is that we analyzed only cases of influenza associated with SARI and did not include cases of mild-to-moderate influenza. However, our analyses of statewide birth outcomes detected substantial periodicity in birthweights and gestational length; poorer outcomes coincided with influenza season. Maternal influenza also might affect other perinatal outcomes, such as medical necessity for caesarean birth. Second, our nested observational descriptive study cannot infer a causal relationship between maternal SARI and

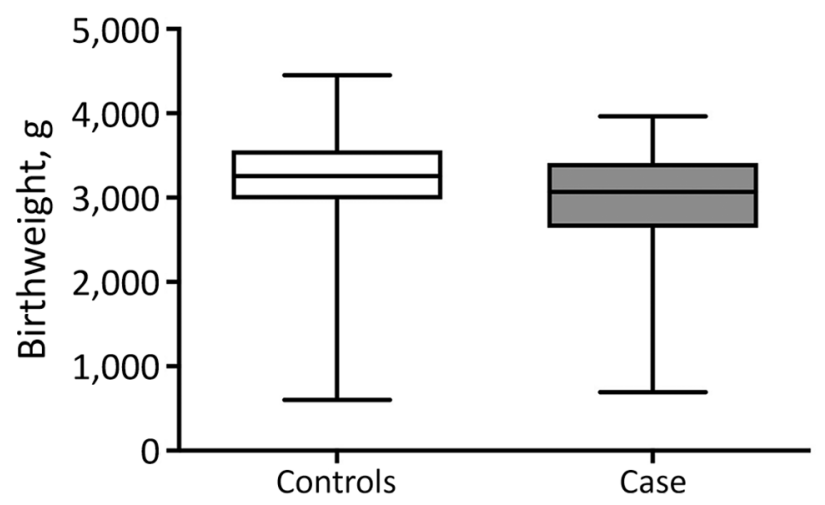

Figure 6. Comparison of birthweights of children born to mothers who did (cases) and did not (controls) have severe acute respiratory infections during pregnancy, Ceará, Brazil, 20132018. Horizontal lines within boxes indicate means; box tops and bottoms indicate 25th and 75th percentiles; whiskers indicate $95 \%$ Cls. $p=0.02$ by Mann-Whitney test. adverse birth outcomes. However, the associations were robust to logistic regression adjusted for several potential confounders. In addition, because hospitalization is part of the case definition for SARI, public and private hospitals (but not private clinics) are required to report SARI cases to SINAN. Although many private clinics do report, most reported cases come from public institutions. Thus, we might not have analyzed all SARI cases in Ceará. Finally, our results suggest that asynchronous vaccination schedules might be associated with adverse influenza outcomes in Ceará, but we did not model the extent to which earlier immunization or the use of vaccine strains from the Northern or Southern Hemispheres might mitigate these outcomes. Recent epidemiologic models suggest Ceará is the starting point for influenza transmission from the semiarid region in southern Brazil, hence earlier immunization in Ceará might have substantial benefits for the region and country (5). We did not account for infections with Zika virus as a potential confounder of our findings because the reported Zika incidence was 0 during 2013-2016; however, testing for Zika was not routinely performed during this time period. The state had low Zika incidence during the study: 5.6 cases $/ 100,000$ persons in 2017 and 0.2 cases/100,000 persons in 2018 (35).

In conclusion, our results show that late timing of influenza vaccination in Ceará, a populous semiarid state in Brazil with high vaccination coverage, correlates with adverse perinatal outcomes. In addition, we found that mean birthweight and rates of prematurity followed an annual periodicity, suggesting additional associations with seasonal influenza. Finally, we confirmed a robust association of maternal SARI with poor birth outcomes using an observational descriptive study design. Further work is urgently needed to model and study the 
optimal timing, potential impact, logistics, economics, and implementation of such a diversified national influenza vaccine strategy. Because Ceará is the presumptive starting point for an annual north-tosouth pattern of seasonal influenza transmission in Brazil (15), our data indicate earlier timing of national immunization campaigns, ideally before seasonal influenza circulation in Ceará, might provide substantial benefits not only for women and children in the semiarid region but also for Brazil as a country.

This article was preprinted at https:/ /www.medrxiv.org/ content/10.1101/2020.08.24.20180455v2.

\section{Acknowledgments}

We thank the staff and data management team at Institute for Biomedicine, School of Medicine, Federal University of Ceará and the Epidemiological Surveillance Information System for Influenza, Ceará State Health Secretariat in Fortaleza, Brazil for database management and linkage.

We dedicate this manuscript to the memory of Dr. Mark Steinhoff, who was a major source of inspiration for these studies.

INFLUEN-SA Brazil was supported by Grand Challenge Explorations - Brazil with funding from the Bill \& Melinda Gates Foundation (grant no. ID OPP1202179), the Conselho Nacional de Desenvolvimento Científico e Tecnológico (grant no. 443771/2018-9), and the Fundação Cearense de Apoio a Pesquisa (grant no. GCE-0014700005.01.00/19). This study was also supported by the Federal University of Ceará Coordination for the Improvement of Higher Education Personnel Print program (Auxílio Financeiro a Projeto Educacional ou de Pesquisa grant no. 88887.311922/2018-00), the Fogarty International Center of the US National Institutes of Health (grant no. K02 TW008767), and the Pendleton Infectious Disease Laboratory Endowment (University of Virginia).

\section{About the Author}

Mr. Filho is a doctoral student at the Federal University of Ceará in Fortaleza, Brazil. His research interests include infectious disease epidemiology and maternal-child health.

\section{References}

1. World Health Organization. The top 10 causes of death. 2020 Dec 9 [cited 2021 Jul 7]. https:/ / www.who.int/news-room/ fact-sheets/detail/the-top-10-causes-of-death

2. Wang X, Li Y, O’Brien KL, Madhi SA, Widdowson MA, Byass $\mathrm{P}$, et al.; Respiratory Virus Global Epidemiology Network. Global burden of respiratory infections associated with seasonal influenza in children under 5 years in 2018: a systematic review and modelling study. Lancet Glob
Health. 2020;8:e497-510. https://doi.org/10.1016/ S2214-109X(19)30545-5

3. Schlaudecker EP, Steinhoff MC, Moore SR. Interactions of diarrhea, pneumonia, and malnutrition in childhood: recent evidence from developing countries. Curr Opin Infect Dis. 2011;24:496-502. https://doi.org/10.1097/ QCO.0b013e328349287d

4. Simonsen L, Clarke MJ, Williamson GD, Stroup DF, Arden NH, Schonberger LB. The impact of influenza epidemics on mortality: introducing a severity index. Am J Public Health. 1997;87:1944-50. https:/ / doi.org/ 10.2105/AJPH.87.12.1944

5. Katz MA, Gessner BD, Johnson J, Skidmore B, Knight M, Bhat N, et al. Incidence of influenza virus infection among pregnant women: a systematic review. [Erratum in: BMC Pregnancy Childbirth. 2017;17:192]. BMC Pregnancy Childbirth. 2017;17:155. https://doi.org/10.1186/ s12884-017-1333-5

6. Fell DB, Sprague AE, Liu N, Yasseen AS III, Wen SW, Smith G, et al.; Better Outcomes Registry \& Network (BORN) Ontario. H1N1 influenza vaccination during pregnancy and fetal and neonatal outcomes. Am J Public Health. 2012;102:e33-40. https:/ / doi.org/10.2105/ AJPH.2011.300606

7. Regan AK, Feldman BS, Azziz-Baumgartner E, Naleway AL, Williams J, Wyant BE, et al. An international cohort study of birth outcomes associated with hospitalized acute respiratory infection during pregnancy. J Infect. 2020;81:4856. https://doi.org/10.1016/j.jinf.2020.03.057

8. Dawood FS, Kittikraisak W, Patel A, Rentz Hunt D, Suntarattiwong P, Wesley MG, et al. Incidence of influenza during pregnancy and association with pregnancy and perinatal outcomes in three middle-income countries: a multisite prospective longitudinal cohort study. Lancet Infect Dis. 2021;21:97-106. https:/ / doi.org/10.1016/S14733099(20)30592-2

9. Mertz D, Geraci J, Winkup J, Gessner BD, Ortiz JR, Loeb M. Pregnancy as a risk factor for severe outcomes from influenza virus infection: A systematic review and meta-analysis of observational studies. Vaccine. 2017;35:5218. https:/ / doi.org/10.1016/j.vaccine.2016.12.012

10. Black RE, Allen LH, Bhutta ZA, Caulfield LE, de Onis M, Ezzati M, et al.; Maternal and Child Undernutrition Study Group. Maternal and child undernutrition: global and regional exposures and health consequences. Lancet. 2008;371:243-60. https://doi.org/10.1016/S0140-6736(07)61690-0

11. Victora CG, Adair L, Fall C, Hallal PC, Martorell R, Richter L, et al.; Maternal and Child Undernutrition Study Group. Maternal and child undernutrition: consequences for adult health and human capital. Lancet. 2008;371:340-57. https://doi.org/10.1016/S0140-6736(07)61692-4

12. Guerrant DI, Moore SR, Lima AAM, Patrick PD, Schorling JB, Guerrant RL. Association of early childhood diarrhea and cryptosporidiosis with impaired physical fitness and cognitive function four-seven years later in a poor urban community in northeast Brazil. Am J Trop Med Hyg. 1999;61:707-13. https://doi.org/10.4269/ajtmh.1999.61.707

13. MAL-ED Network Investigators. Early childhood cognitive development is affected by interactions among illness, diet, enteropathogens and the home environment: findings from the MAL-ED birth cohort study. BMJ Glob Health. 2018;3:e000752. https://doi.org/10.1136/bmjgh-2018-000752

14. Takeda S, Hisano M, Komano J, Yamamoto H, Sago H, Yamaguchi K. Influenza vaccination during pregnancy and its usefulness to mothers and their young infants. J Infect Chemother. 2015;21:238-46. https://doi.org/10.1016/ j.jiac.2015.01.015 
15. Almeida A, Codeço C, Luz PM. Seasonal dynamics of influenza in Brazil: the latitude effect. [Erratum in: BMC Infect Dis. 2018;19:225]. BMC Infect Dis. 2018;18:695. https:/ / doi.org/10.1186/s12879-018-3484-z

16. Moura FEA, Perdigão ACB, Siqueira MM. Seasonality of influenza in the tropics: a distinct pattern in northeastern Brazil. Am J Trop Med Hyg. 2009;81:180-3. https:// doi.org/ 10.4269/ajtmh.2009.81.180

17. Instituto Brasileiro de Geografia e Estatística. Fortaleza. 2017 [2021 July 7]. https:/ / cidades.ibge.gov.br/brasil/ce/ fortaleza/panorama

18. Ministério da Saúde. Edict no. 1,271, June 6, 2014 [in Portuguese]. 2014 [2021 Jul 9]. https:/ / bvsms.saude.gov.br/ bvs/saudelegis/gm/2014/prt1271_06_06_2014.html

19. Sistema de Informação de Agravos de Notificação. SINAN influenza. 2016 [cited 2021 Jul 7]. https:/ / portalsinan.saude. gov.br/sinan-influenza

20. World Health Organization. Global epidemiological surveillance standards for flu. 2014 [cited 2019 Dec 18]. https://apps.who.int/iris/handle/10665/311268

21. Monto AS, Gravenstein S, Elliott M, Colopy M, Schweinle J. Clinical signs and symptoms predicting influenza infection. Arch Intern Med. 2000;160:3243-7. https:/ / doi.org/10.1001/ archinte.160.21.3243

22. Yang JH, Huang PY, Shie SS, Yang S, Tsao KC, Wu TL, et al. Predictive symptoms and signs of laboratory-confirmed influenza: a prospective surveillance study of two metropolitan areas in Taiwan. Medicine (Baltimore). 2015;94:e1952. https://doi.org/10.1097/MD.0000000000001952

23. World Health Organization. WHO information for the molecular detection of influenza viruses. 2017 [cited 2021 Jul 7]. https://www.who.int/influenza/gisrs_laboratory/ WHO_information_for_the_molecular_detection_of_ influenza_viruses_20171023_Final.pdf

24. Global Health Data Exchange. Brazil live birth information system. 2018 [cited 2021 Jul 7]. http:/ /ghdx.healthdata.org/ series/brazil-live-birth-information-system-sinasc

25. Kirkwood BR, Sterne JAC. Essential medical statistics. Malden (MA): Wiley-Blackwell; 2003.

26. Tabachnick BG, Fidell LS. Using multivariate statistics. 6th ed. New York: Harper and Row; 2012.

27. Simonsen L, Taylor R, Viboud C, Dushoff J, Miller M. US flu mortality estimates are based on solid science. BMJ. 2006;332:177-8. https:// doi.org/10.1136/bmj.332.7534.177-a

28. Glezen WP, Keitel WA, Taber LH, Piedra PA, Clover RD, Couch RB. Age distribution of patients with medicallyattended illnesses caused by sequential variants of influenza A/H1N1: comparison to age-specific infection rates, 1978-1989. Am J Epidemiol. 1991;133:296-304. https://doi.org/10.1093/oxfordjournals.aje.a115874

29. Bhat N, Wright JG, Broder KR, Murray EL, Greenberg ME, Glover MJ, et al.; Influenza Special Investigations Team. Influenza-associated deaths among children in the United States, 2003-2004. N Engl J Med. 2005;353:2559-67. https://doi.org/10.1056/NEJMoa051721

30. Omer SB, Goodman D, Steinhoff MC, Rochat R, Klugman KP, Stoll BJ, et al. Maternal influenza immunization and reduced likelihood of prematurity and small for gestational age births: a retrospective cohort study. PLoS Med. 2011;8:e1000441. https://doi.org/10.1371/ journal.pmed.1000441

31. Dodds L, MacDonald N, Scott J, Spencer A, Allen VM, McNeil S. The association between influenza vaccine in pregnancy and adverse neonatal outcomes. J Obstet Gynaecol Can. 2012;34:714-20. https://doi.org/10.1016/ S1701-2163(16)35336-1

32. Giles ML, Krishnaswamy S, Macartney K, Cheng A. The safety of inactivated influenza vaccines in pregnancy for birth outcomes: a systematic review. Hum Vaccin Immunother. 2019;15:687-99. https:// doi.org/10.1080/ 21645515.2018.1540807

33. Niehaus MD, Moore SR, Patrick PD, Derr LL, Lorntz B, Lima AA, et al. Early childhood diarrhea is associated with diminished cognitive function 4 to 7 years later in children in a northeast Brazilian shantytown. Am J Trop Med Hyg. 2002;66:590-3. https://doi.org/10.4269/ ajtmh.2002.66.590

34. Lorntz B, Soares AM, Moore SR, Pinkerton R, Gansneder B, Bovbjerg VE, et al. Early childhood diarrhea predicts impaired school performance. Pediatr Infect Dis J. 2006;25:513-20. https://doi.org/10.1097/01. inf.0000219524.64448.90

35. Governo do Estado do Ceará. Epidemiological Bulletin, Congenital Syndrome Associated with Zika Virus Infection [in Portuguese]. 2018 [cited 2021 Jul 7]. https:/ /www.saude. ce.gov.br/wp-content/uploads/sites/9/2018/06/ boletim_microcefalia_30_05_2018.pdf

Address for correspondence: Aldo A.M. Lima, R. Cel. Nunes de Melo, 1315, Rodolfo Teófilo, Fortaleza, Ceará, CEP 60.430-270, Brazil; email: alima@ufc.br; Sean R. Moore, MR-4 Bldg, 409 Lane Rd, Rm 2129, Charlottesville, VA 22908, USA; email: srm5u@virginia.edu 